\title{
Winter ischaemic heart disease deaths in Birmingham, United Kingdom: a synoptic climatological analysis
}

\author{
Glenn R. M cG regor* \\ The School of G eography and Environmental Sciences, The University of Birmingham, Birmingham B15 2TT, \\ United Kingdom
}

\begin{abstract}
The relationship between winter ischaemic heart disease (IHD) deaths and weather is investigated using a synoptic climatological approach. First the main air mass types affecting the study area are identified and then an assessment of the extent of the statistical relationship between mortality and the identified air mass types is made. Within air mass type meteorology-mortality relationships are also explored. Study results show that increased mortality rates are associated with 2 air mass types with contrasting physical properties: a cold polar continental type associated with an anticyclonic system lying over the European continent to the north or east of the study area and a moderately warm blustery maritime type that occurs as an Atlantic ocean low pressure system approaches the study area. An analysis of air mass sequences also demonstrates that IHD mortality is related to air mass change. Results are discussed in terms of methodologies for climate mortality studies.
\end{abstract}

KEY WORDS: Synoptic climatology · Air masses · Ischaemic heart disease $\cdot$ M ortality $\cdot$ United Kingdom

\section{INTRODUCTION}

Studies of the link between atmospheric variables, loosely referred to as the weather, and health have a long history (Driscoll 1971, Tromp 1980, Tout 1987, Curson 1996, M cM ichael et al. 1996, Martens 1998). A characteristic of many of these studies however is the simple treatment of weather as a single, or at best, a 2-variable (temperature and humidity) phenomenon (Tselepidaki et al. 1995, Eurowinter Group 1997). Climate and weather are, however, the manifestation of the synergistic behaviour of a range of atmospheric variables. This behaviour expresses itself in the form of air masses, which can be defined as large bodies of air with relatively homogeneous temperature, humidity and stability characteristics. The long- and short-term temporal and spatial variability of air masses produces the climate of and brings the daily weather changes experienced at a location. Given this, a logical and

*E-mail: g.r.mcgregor@bham.ac.uk alternative approach to the assessment of climate-mortality relationships would be to search for the existence of links between mortality and the spectrum of air mass types or weather situations that may affect a location. Such an approach makes sense not only from the climatological but also the biometeorological point of view as the human body responds to the totality of the atmospheric environment as encapsulated by air mass types. Furthermore, the human body may respond differently to contrasting air mass types or weather situations or combinations of these.

Despite the theoretical justification for applying an air mass based approach to the analysis of weatherhealth relationships, few recent studies have adopted this approach. This is of interest as, in an extensive review of the literature on weather health relationships for the years 1935 to 1968, Driscoll (1971) noted a trend away from analyses of health outcomes in terms of individual atmospheric elements to analyses based on synoptic climatological characteristics such as air mass types and the occurrence or non-occurrence of fronts. Unfortunately, this trend appears to have not been 
sustained as only a few climate and health studies based on a synoptic approach have appeared in the literature since the early 1980s (Balling 1984, Muller \& J ackson 1985, Anto \& Sunyer 1986, Sanchez 1990, Driscoll 1992, Jendritzky \& Bucher 1992, Bucher \& Hasse 1993).

Perhaps the greatest advances in the application of air mass based approaches to the analysis of weather/ climate and health relationships have come from the University of Delaware (United States) school of synoptic climatology (Kalkstein 1991, Kalkstein \& Smoyer 1993, Greene \& Kalkstein 1996, Kalkstein \& Greene 1997). Regrettably, the application of the 'Delaware approach' to the analysis of weather-health relationships has, as yet, not been applied outside the United States despite its proven utility for shedding light on a range of climate and health issues (M CMichael et al. 1996).

The aim of this paper is therefore to apply the air mass based approach, as described by Kalkstein (1991), to the analysis of weather and health relationships for the Birmingham area, United Kingdom. The health outcome considered is winter ischaemic heart disease (IHD) mortality as this accounts for around $64 \%$ of the total daily winter deaths due to IHD and chronic obstructive pulmonary and cerebrovascular disease for the study area. Specifically, this study attempts to assess whether statistically significant relationships exist between air mass types and IHD mortality.

This paper is organised into 6 parts. In Section 2 the methodology will be presented. The air mass types or weather situations identified for the study period will be described in Section 3. The association between weather and IHD mortality will be assessed in Section 4 using firstly a traditional correlation based epidemiological approach and secondly an air mass based approach. In Section 5 the extent to which certain air mass sequences provide the requisite meteorological conditions for elevated IHD mortality will be assessed. Study results will be discussed in Section 6 and conclusions drawn in Section 7.

\section{METHODOLOGY}

A winter only analysis is presented here because winter (November to February) possesses the highest mean and most variable mortality rates for IHD. The methodology follows 3 broad steps which are at the heart of the synoptic climatological approach to the analysis of general atmosphere-environment relationships (Yarnal 1993). These are firstly the identification of air mass types (AT) using standard meteorological data, secondly the characterisation of these in terms of
IHD deaths and thirdly the exploration of air mass type IHD mortality linkages using stepwise regression analysis. For this study a simple mortality index referred to as the IHDINDEX was calculated to express mortality as a percentage of the mean daily mortality rate for the 6-winter study period. An IHDINDEX value of 100 is interpreted as the mean winter rate of 10.4 deaths $\mathrm{d}^{-1}$.

The identification of winter air mass types was based on the use of standard meteorological data for the winters (NDJ F) 1988-89 to 1993-94 in conjunction with principal components analysis (PCA) followed by cluster analysis (CA). The outcome of the application of these 2 techniques is a temporal synoptic index (TSI) from which a daily calendar of air mass types may be constructed. The utility of the TSI for studying weather-health linkages for a single location has been outlined by Kalkstein (1991). Furthermore such techniques have proved useful for analyses of air quality, weather and respiratory disease relationships in the study area (McGregor \& Bamzelis 1995, McGregor et al. 1999). It is acknowledged here that, although air masses are truly 3-dimensional, the unavailability of upper air data for the study area precluded categorisation according to their three-dimensional character. The air mass descriptions presented are therefore for surface characteristics only.

The meteorological variables used in the analysis were either directly measured or estimated from data collected at 09:00 and 15:00 $\mathrm{h}$ at the University of Birmingham, School of Geography automatic weather station (AWS) which has been ratified by the United Kingdom Meteorological Office as a representative regional climate station. Variables included dry bulb temperature, mixing ratio, cloud cover, atmospheric pressure, meridional and zonal wind components and wind speed. The meteorological data set for input into the PCA thus comprised 14 variables ( 7 variables twice daily) $\times 662 \mathrm{~d}$ (59d were not available for J anuary and February 1994). Deaths with the Classification of Disease coding IHD 410.0 to 414.9 were extracted from records obtained from the West Midlands Health Authority and form the IHD mortality data set for the study.

Multiple stepwise regression analysis was used to explore the nature of the linkage between a range of independent meteorological variables and the dependent IHD mortality variable for each of the air mass types. Two sets of variables made up the independent meteorological data set; the variables used to construct the air mass types and a set of large-scale atmospheric circulation variables (Table 1). All meteorological variables met the condition of a normal distribution as established by a Kolmogorov-Smirnov test (Ebdon 1985). In the case that highly inter-correlated variables 
Table 1. Variables used in multiple stepwise linear regression analyses

\begin{tabular}{|c|c|}
\hline Variables & Description \\
\hline Ta9 and Ta15 & Dry bulb temperature at 09:00 and $15: 00 \mathrm{~h}$ respectively $\left({ }^{\circ} \mathrm{C}\right)$ \\
\hline Tdew9 and Tdew15 & Dew point temperature at $09: 00$ and $15: 00 \mathrm{~h}$ respectively $\left({ }^{\circ} \mathrm{C}\right)$ \\
\hline SLP9 and SLP15 & Sea level pressure at 09:00 and 15:00 $\mathrm{h}$ respectively $(\mathrm{hPa})$ \\
\hline$u 9$ and $v 9, u 15$ and $v 15$ & Local Birmingham westerly $(\mathrm{u})$ and southerly $(\mathrm{v})$ wind components at 09:00 and 15:00 h respectively \\
\hline ws9 and ws15 & Local Birmingham wind speed at 09:00 and 15:00 $\mathrm{h}$ respectively $\left(\mathrm{m} \mathrm{s}^{-1}\right)$ \\
\hline W & Large-scale mean daily zonal wind component (hPa per $10^{\circ}$ at $55^{\circ} \mathrm{N}$ ) \\
\hline $\mathrm{S}$ & Large-scale mean daily meridional wind component (hPa per $10^{\circ}$ at $55^{\circ} \mathrm{N}$ ) \\
\hline Z & Large-scale mean daily total vorticity (hPa per $10^{\circ}$ at $\left.55^{\circ} \mathrm{N}\right)$ \\
\hline ZW & Large-scale mean daily westerly shear vorticity (hPa per $10^{\circ}$ at $\left.55^{\circ} \mathrm{N}\right)$ \\
\hline $\mathrm{ZS}$ & Large-scale mean daily southerly shear vorticity (hPa per $10^{\circ}$ at $55^{\circ} \mathrm{N}$ ) \\
\hline $\mathrm{T}-1$ & Indicates variable lagged by $1 \mathrm{~d}$ \\
\hline $\mathrm{d} / \mathrm{dt}$ & $\begin{array}{l}\text { Indicates change over previous } 24 \mathrm{~h} \text { for example dTdew } 9 / \mathrm{dt} \text { is change of 09:00 } \mathrm{h} \text { dew point temp- } \\
\text { erature from previous day }\end{array}$ \\
\hline
\end{tabular}

(correlation coefficient greater than 0.7) appeared in the regression equations, such as dry bulb and dew point temperatures, one of these variables was removed and the regression analysis performed again.

\section{EMERGENT AIRMASS TYPES}

A pplication of a P mode PCA (Yarnal 1993) resulted in 4 principal components being identified. These accounted for $71.6 \%$ of the original data variance. Clustering of principal component scores resulted in 6 major air mass types being identified. The main meteorological characteristics of the air mass types as described by University of Birmingham AWS data and large-scale atmospheric circulation variables (see below) are summarised graphically in Fig. la-f. Representative synoptic charts for each air mass type are presented in Fig. 2a-f. These were selected based on an analysis of the cluster analysis dendrogram. Synoptic weather charts for days at and around the centroid for each of the 6 clusters were inspected. For each cluster the number of days inspected was equivalent to $25 \%$ of the number of days making up the cluster. A chart representative of these days was then selected to portray the general synoptic-scale situation associated with the air mass type. The air mass types and their associated weather situations are described below. To lend a large-scale element to these descriptions, additional atmospheric circulation variables derived from a coarse $5^{\circ}$ by $10^{\circ}$ grid of mean sea level pressure covering the region between $70^{\circ}$ and $40^{\circ} \mathrm{N}$ and $25^{\circ} \mathrm{W}$ to $15^{\circ} \mathrm{E}$ were also used. The variables are geostrophic and are expressed as $\mathrm{hPa}$ per $10^{\circ}$ at $55^{\circ} \mathrm{N}$ and include zonal and meridional wind components, total vorticity and westerly and southerly shear vorticity (Table 1) as described in Kilsby et al. (1998).
3.1. AT 1. Polar maritime. Strong moderately cool dry northwest flows associated with cyclonic vorticity typify AT1 (Fig. 1e,h). Rapidly falling temperatures and moisture levels but decreasing southerliness of flow are a distinct feature (Fig. $1 \mathrm{i}, \mathrm{j}, \mathrm{m}$ ). Over an AT1 sequence there is a tendency for pressure to fall and cyclonic vorticity to increase (Fig. $1 k, I)$. The synopticscale situation is dominated by rapid eastwardly moving depressions to the north of the UK (Fig. 2a).

3.2. AT2. Moist anticyclonic. Moderately cool moist weak southwesterly to northwesterly flows associated with anticyclonic vorticity are a distinct characteristic of AT2 (Fig. 1h). The moderately high atmospheric moisture levels tend to increase over an AT2 sequence. Heavily overcast conditions well above the winter average exist (Fig. 1C). Temperature changes are generally limited to $\pm 2^{\circ} \mathrm{C}$ (Fig. 1i). Pressure is moderately high and tends to demonstrate a small increase, as does anticyclonic vorticity (Fig. 1k, I). Associated with these trends is a decreasing westerliness of the largescale flow but little change in the meridional component (Fig. Im, n). A well-developed anticyclonic system which lies over the UK with a meridional orientation of isobars typifies the AT2 situation (Fig. 2b).

3.3. AT3. Tropical maritime. Warm and moist southwesterly flows associated with weak large-scale anticyclonic vorticity characterise this type (Fig. If-h). Cloud cover is generally high but variable (Fig. 1c). Increasing temperature and moisture levels as well as strengthening southerly and westerly wind components are a feature (Fig. 1i,j). There is a weak tendency to increasing vorticity levels over AT3 sequences (Fig. 1l). A trough of low pressure lies to the west of the UK. This often extends to subtropical latitudes and is responsible for the advection of warm moist air over the UK. Imbedded in the trough are weak centres of low pressure to the northwest and southwest of the UK. 

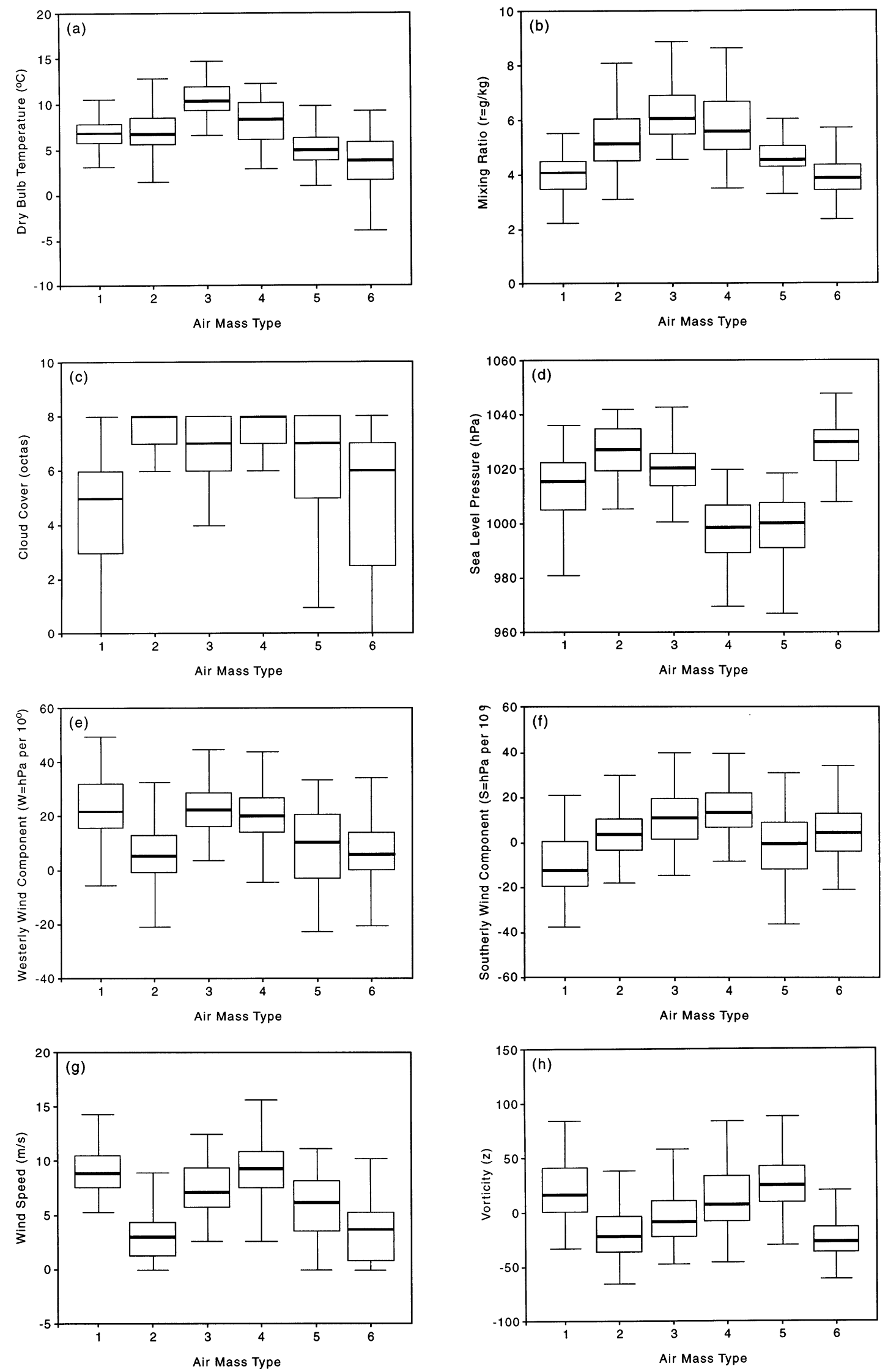

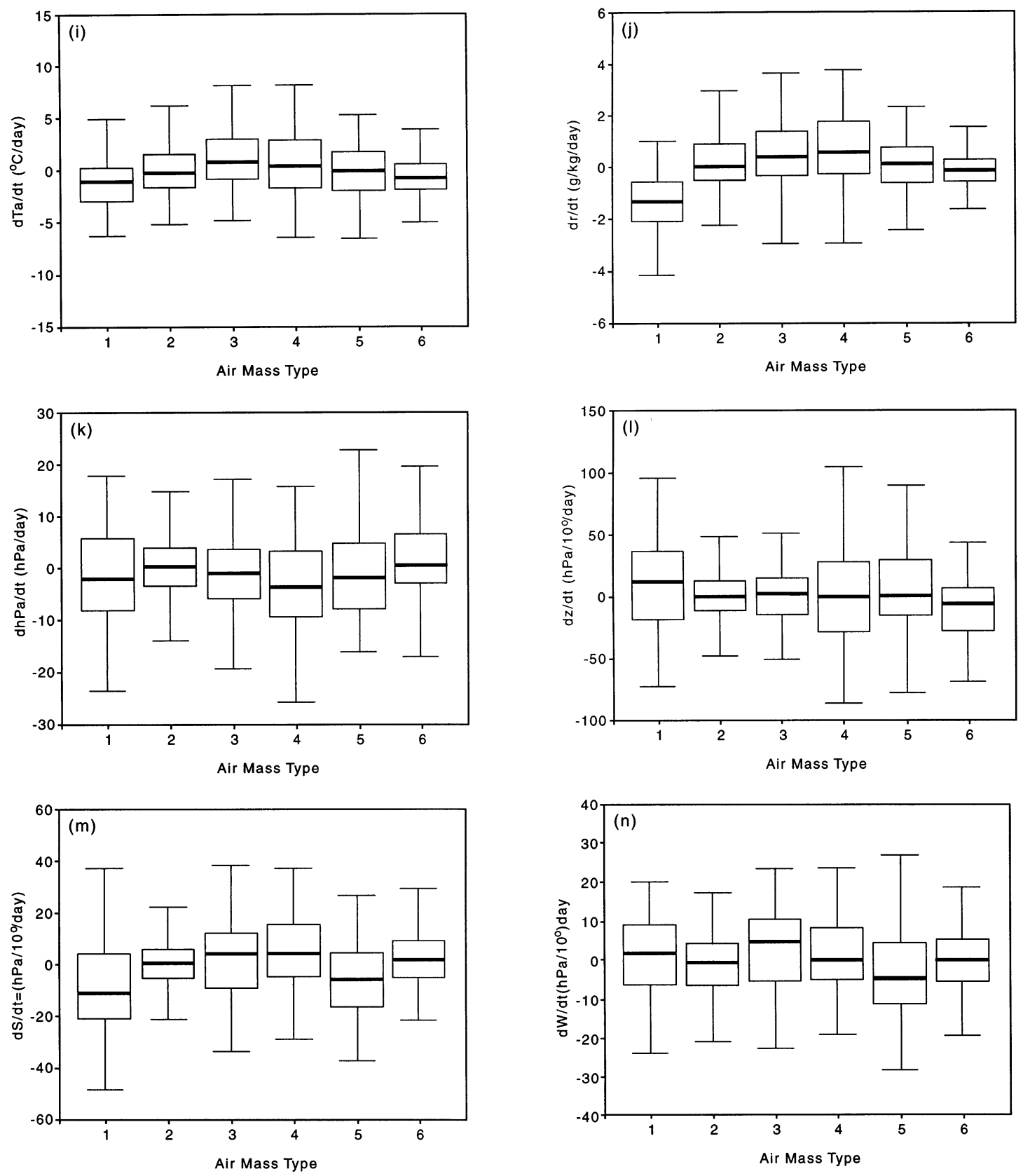

Fig. 1. (Facing page and above.) M eteorological characteristics of winter air mass types. (a-k) Variables measured at Birmingham; $(\mathrm{I}-\mathrm{n})$ large-scale circulation variables with units of $\mathrm{hPa}$ per $10^{\circ}$ latitude at $55^{\circ} \mathrm{N}$ derived from a coarse pressure grid (see text for details)

A moderately well-developed anticyclone lies over eastern Europe. Over western Europe pressure gradients are weak (Fig. 2C). AT3 is the warmest and most humid of the winter air mass types (Fig. 1a,b). This is a transitional type between AT2 and AT4.

3.4. AT4. Mid-latitude maritime air mass characterised by moderately warm moist but very strong southwesterly flows and very overcast conditions (Fig. 1c,e,f). At the large-scale a moderately intense low pressure dominates the atmospheric circulation over the majority of the northeast Atlantic and northwestern Europe (Figs. $1 \mathrm{~h} \& 2 \mathrm{~d}$ ). AT4 is generally characterised by increasing temperature and moisture levels, strengthening southwestery flows, falling pressure and increasing cyclonic vorticity (Fig. $1 \mathrm{i}-\mathrm{m}$ ). These trends are associated with the rapid movement of a centre of low pressure and its attendant fronts from the mid-N orth Atlantic towards the UK (Fig. 2d). 

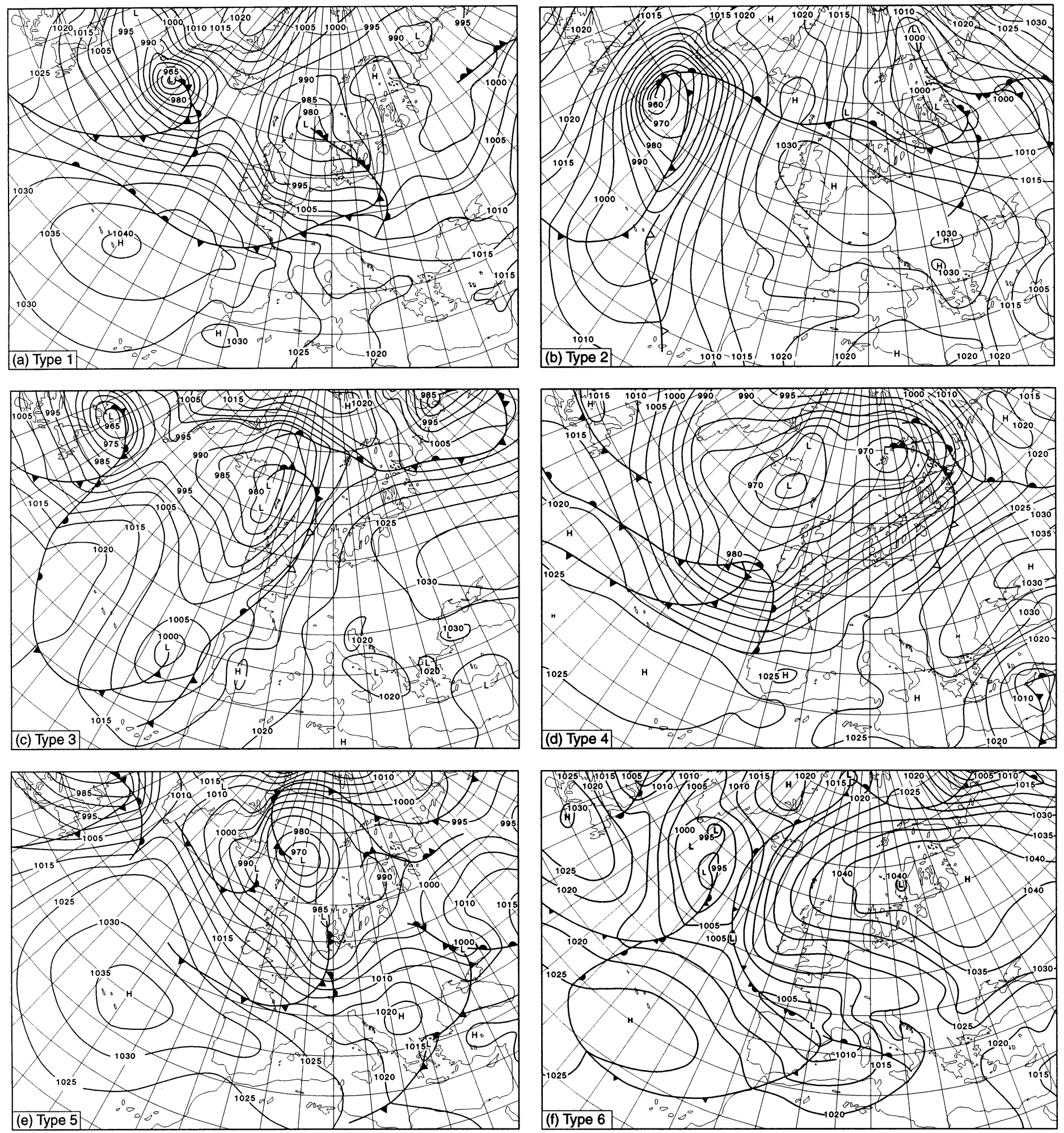

Fig. 2. Representative synoptic charts for the 6 winter air mass types

3.5. AT5. Sub-polar maritime. This air mass is characterised by cool moderately moist westerly to northwesterly flows (Fig. 1a-f). Slight temperature and moisture level increases or decreases occur with this air mass.
However, for the majority of AT5 days these changes are limited to a small range: $\pm 2^{\circ} \mathrm{C}$ for temperature $\pm 1 \mathrm{~g}$ $\mathrm{kg}^{-1}$ for the mixing ratio (Fig. $1 \mathrm{i}, \mathrm{j}$ ). Cloud cover is high but there is some variation between days (Fig. 1c). The 
circulation features associated with AT5 are typically a well-developed anticyclonic system over the midAtlantic and a moderately intense cyclonic system north of the UK lying between Iceland and Scandanavia. This configuration results in the advection of cool moist air over the UK from the northwest (Fig. 2e). Atmospheric pressure is generally low but pressure tendencies during AT 5 days vary. Falling pressures are a product of the advance of a sub-polar cyclonic system eastwards towards the UK. Rising pressure follows the eastward progression of the cyclonic system as the midAtlantic anticyclonic system becomes more dominant. AT5 possesses the greatest cyclonic vorticity of the winter air mass types (Fig. Ih).

3.6. AT6. Sub-polar continental anticyclonic. Air mass characteristics are typified by cold generally dry conditions (Fig. 1a,b). These are associated with high and increasing atmospheric pressure and anticyclonic vorticity (Fig. 1d, h,l). Generally, wind speeds are low with very weak southerly and westerly components (Fig. le-g). Cloud cover statistics for this type are strongly negatively skewed to low values. Completely clear skies are a frequent occurrence (Fig. 1C). On many occasions conditions are calm; however, strong easterly flows which bring snow to the study area may occur. On AT6 days temperature and moisture levels generally remain low with little change (Fig. $1 \mathrm{i}, \mathrm{j}$ ). At the large scale the atmospheric circulation situation is dominated by a well-developed anticyclonic system lying over Europe with a ridge of high pressure extending westward over the UK (Fig. 2f). This situation results in the advection of cold dry continental air over the UK. AT6 is the coldest (Fig. 1a) and the most anticyclonic (Fig. Ih) of the winter air mass types.

\section{WEATHER AND MORTALITY RELATIONSHIPS}

In this section the association between weather and mortality will be assessed. This assessment will be undertaken in 3 stages. Firstly in Section 4.1 a traditional analysis of weather mortality relationships will be conducted using stepwise multiple linear regression analysis. This will be followed in Section 4.2 by an assessment of the hypothesis that air mass types possess differential mortality levels and they therefore

Table 2. Multiple stepwise linear regression results for all 662 winter days

\begin{tabular}{|lcc|}
\hline Variables & $\mathrm{r}^{2}$ & $\mathrm{p}$ \\
\hline $\mathrm{Ta}_{(\mathrm{T}-1)}$ & 0.014 & 0.007 \\
$\mathrm{ZW}(\mathrm{T}-1)$ & & \\
$\mathrm{S}$ & & \\
\hline
\end{tabular}

provide a suitable climatological context for analysing weather-mortality relationships. The third and final stage involves an assessment of the idea that weathermortality relationships vary for the air masses identified in Section 3 given that the human body may respond differently to contrasting weather situations.

\subsection{Linear regression analysis and weather-mortality relationships}

Daily IHD data was regressed against a range of meteorological variables, as described in Table 1. Stepwise multiple regression analysis results revealed a significant relationship between daily mortality and 3 variables at the 0.001 level (variables were entered [removed] from the multiple regression model based on an $\mathrm{F}$ value of 0.05 [0.10]). Although the relationship is very weak $\left(r^{2}=0.014\right)$ the variables in Table 2 indicate that daily mortality on Day $T$ is sensitive to low afternoon temperatures (Ta15) and high westerly shear vorticity (ZW) on Day T-1 and a strong southerly wind component (S) on Day $\mathrm{T}$ (Table 2). These results suggest that elevated mortality rates may be associated with cool vigorous flows from the west backing to the south. However, in terms of meteorology and the dynamics of weather systems such a sequence of events is difficult to account for. The regression results are therefore somewhat contradictory and most likely represent competing independent relationships between the regression variables and mortality. Such competing effects may be due to the fact that there is an element of equifinality in weather-mortality relationships such that elevated mortality rates may be associated with markedly different weather situations. This supposition is tested in the next section.

\subsection{Air mass mortality relationships}

Descriptive statistics for mortality by air mass type are presented in Table 3. Although there appears to be little contrast in mean and median mortality levels among the air mass types, the application of an analysis of variance (ANOVA) test revealed significant interair mass type differences in mean daily mortality rate at the 0.02 level (Table 4). However when an honestly significant difference (HSD) test (Tukey 1953) was conducted, to establish which of the air mass type pairs are significantly different, it was found that only AT6 and AT2 possessed significantly different mortality rates at the 0.01 level; AT6 possesses higher daily mortality rates than AT2. This is noteworthy as these air mass types are both anticyclonic but contrast in terms of their moisture and temperature characteristics. 
Table 3. Daily mortality statistics by air mass type (AT). $n$ is number of days on which each air mass occurred; percentage occurrence is given in parentheses. $X, M d, M$ in and $M$ ax are mean, median, minimum and maximum respectively. IHDINDEX > 150 is the number of days and the percentage of $44 \mathrm{~d}$ (in parentheses) when mortality was greater or equal to 1.5 times the overall winter average of 10.4 deaths $\mathrm{d}^{-1}$

\begin{tabular}{|lrrrrrr|}
\hline AT & $\mathrm{n}(\%)$ & $\mathrm{X}$ & Md & Min & Max & $\begin{array}{c}\text { IHDINDEX } \\
150(\%)\end{array}$ \\
\hline 1 & $72(10.9)$ & 10.0 & 10.0 & 3 & 19 & $5(11.4)$ \\
2 & $166(25.1)$ & 9.8 & 10.0 & 1 & 20 & $5(11.4)$ \\
3 & $118(17.8)$ & 9.9 & 9.0 & 3 & 20 & $5(11.4)$ \\
4 & $83(12.5)$ & 10.9 & 11.0 & 2 & 25 & $8(18.2)$ \\
5 & $71(10.7)$ & 10.7 & 10.0 & 4 & 21 & $6(13.6)$ \\
6 & $152(23.0)$ & 11.0 & 10.5 & 3 & 24 & $15(34.0)$ \\
Total: & $662(100)$ & & & & & $44(100)$ \\
\hline
\end{tabular}

rence for days with mortality levels less than half the overall winter average (the 0-49 class). Inter-air mass type contrasts can also be seen if the 100-149 and >150 classes are aggregated to give the probability, for each air mass type, that the mortality rate will be greater than the winter average. Such an aggregation reveals a clear contrast in conditional probabilities for AT1, AT2, AT3 and AT4, AT5, AT6; the former group has probabilities varying between 38.1 and $42.8 \%$ whereas the latter groups' conditional probabilities range between 49.3 and $54.2 \%$. The greatest contrast is between AT3 and AT4 as the latter possesses a $16.1 \%$ greater chance of

In terms of severe mortality events, defined as days with mortality rates exceeding 1.5 times the 1988-89 to 1993-94 winter average (IHDINDEX > 150), clear interair mass type contrasts are evident. For example AT6 and AT4 appear to account for a disproportionately high percentage of severe mortality days (34.0 and $18.2 \%$ respectively) considering they occurred 23.0 and $12.5 \%$ of the time, respectively, during the study period (Table 3). The opposite is true for AT2. Despite its high frequency of occurrence $(25 \%)$ only $11.4 \%$ of the severe mortality days are associated with this air mass (Table 3). This observation supports the findings of the HSD test and suggests that there is a degree of dependence of mortality level on air mass type such that AT6 and AT4 (AT2 and AT3) possess disproportionately high (low) numbers of high mortality days. In order to test this hypothesis mortality data was classified into 4 IHDINDEX classes (0-49, 50-99, 100-149, $>150$ ), and cross-tabulated with air mass frequency. A 2-sample chi-square analysis (Ebdon 1985) was then conducted to assess whether mortality rate is statistically significantly related to air mass type. Analysis results revealed a weak relationship between mortality rate and air mass type (significant at the 0.09 level, $\chi^{2}=$ 22.6, $\mathrm{df}=15$ ). This dependence can best be understood by a consideration of conditional probabilities. These are interpreted as the probability of a certain mortality level being attained given the occurrence of a specified air mass type.

Conditional probabilities are displayed in Table 5 for the same mortality rate classes as used for the chisquare analysis. These show inter-air mass type differences for the IHDINDEX 0-49 and >150 classes. Notable is the higher probability of a severe mortality day (IHDINDEX > 150) occurring, compared to the other air mass types, given the occurrence of AT6 and AT4. AT6 also possesses a low probability of occurabove average daily winter mortality: 54.2 (AT4) compared to $38.1 \%$ (AT3).

Given the above, it is likely that the distribution of mortality amongst the air mass types is not proportional to the frequency of occurrence of the air mass types. To test this hypothesis a 1 sample chi-square analysis was conducted. Chi-square analysis results $\left(\chi^{2}\right.$ $=15.19$ ) indicate that there is a significant difference at the 0.01 level $\left(\chi_{0.01}^{2}=15.08\right.$ for 5 degrees of freedom) in the proportion of the total mortality shared by the 6 air mass types (Table 6). Examination of the chi-square table reveals which air mass types contribute to the

Table 4. ANOVA test results of difference of mean mortality between air mass types

\begin{tabular}{|lcrrrrr|}
\hline & $\begin{array}{c}\text { Sum of } \\
\text { squares }\end{array}$ & df & $\begin{array}{c}\text { Mean } \\
\text { square }\end{array}$ & $F$ & $p$ \\
\hline $\begin{array}{l}\text { Between } \\
\text { group }\end{array}$ & 156.942 & 5 & 31.388 & 2.667 & 0.021 \\
$\begin{array}{l}\text { Within } \\
\text { group } \\
\text { Total }\end{array}$ & 7720.287 & 656 & 11.769 & & \\
\hline
\end{tabular}

Table 5. Conditional probabilities (\%) by air mass type (AT). Value given is the percentage probability that a given IHDINDEX class will occur given the occurrence of the specified air mass type

\begin{tabular}{|lrrrrrr|}
\hline IHDINDEX & AT1 & AT2 & AT3 & AT4 & AT5 & AT6 \\
\hline $0-49.9$ & 6.9 & 9.0 & 5.1 & 5.1 & 4.2 & 2.6 \\
$50-99.9$ & 52.8 & 48.2 & 56.8 & 40.7 & 46.5 & 47.4 \\
$100-149.9$ & 33.3 & 39.8 & 33.9 & 44.6 & 40.8 & 40.1 \\
$>150$ & 6.9 & 3.0 & 4.2 & 9.6 & 8.5 & 9.9 \\
\hline
\end{tabular}


Table 6. Chi-square test for comparison of distribution of observed and expected mortality by air mass type. Expected $(E)$ : the product of the percentage occurrence of air mass type (Table 3) and total deaths during the $662 \mathrm{~d}$ study period (6877)

\begin{tabular}{|lcccc|}
\hline AT & Observed (O) & Expected (E) & O -E & $(\mathrm{O}-\mathrm{E})^{2} / \mathrm{E}$ \\
\hline 1 & 726 & 749 & -23 & 0.71 \\
2 & 1641 & 1726 & -85 & 4.19 \\
3 & 1173 & 1224 & -51 & 2.13 \\
4 & 907 & 860 & 47 & 2.57 \\
5 & 762 & 736 & 26 & 0.92 \\
6 & 1668 & 1582 & 86 & 4.67 \\
Total: & 6877 & 6877 & & 15.19 \\
\hline
\end{tabular}

significant chi-square statistic and thus possess disproportionately high or low total mortality. Of the 6 air mass types, AT6 and AT4 possess disproportionately high total mortality (observed > expected) while AT2 and AT3 have lower than expected total mortality (observed < expected) (Table 6). This is an important finding given the contention that high mortality rates may result from contrasting weather situations as, in meteorological terms, AT4 and AT6 are markedly different to AT2 and AT3. These findings aid with an understanding of the contradictory regression analysis findings presented in Section 4.1. The relationship of $\mathrm{ZW}$ and $\mathrm{S}$ with mortality (Table 2 ) is attributable to the association between AT4 (intense Atlantic cyclonic storms) and high mortality rates. In contrast the appearance of Ta15 in the regression analysis results relates to the association of high mortality rates with AT6 conditions (cold easterly continental anticyclonic flows). Assuming that such independent effects are at play it might be expected that weather-mortality relationships vary according to the air mass type or weather situation. This contention is addressed in the following section.

\subsection{Weather-mortality relationships for individual air mass types}

Relationships between weather and mortality for the individual air mass types were investigated using stepwise multiple linear regression analysis as in Section 4.1. Although this method is the same as used in conventional epidemiological studies the approach taken here is different as the IHD and meteorological data are stratified according to air mass type or weather situation. In this section weather-mortality relationships are explored at 2 levels. Firstly, associations between weather and mortality are assessed for all days belonging to each of the 6 air mass types. Secondly, the same sort of analyses are conducted for days falling within the upper quartile for mortality. The intent of this section is to show how IHD mortality varies within each of the air mass types.

Results of the analyses of weather mortality relationships for all days by air mass type are shown in Table 7. The main results can be summarised as follows:

- The relationships between weather and mortality are stronger for 5 of the 6 air masses (Table 7) compared to that revealed in the analysis for all days regardless of weather situation (Table 2 ).

- The degree of dependency of mortality on weather as described by $r^{2}$ varies among the air masses; the weather sensitivity of mortality is greatest for AT1 and AT4 and least for AT2 and AT3.

- As for the overall regression analysis (Table 2) both lagged $(T-1)$ and concurrent $(T)$ meteorological variables are associated with mortality for some air mass types.

- Large-scale atmospheric circulation variables, namely southerly and westerly shear vorticity, appear important for explaining variations in mortality for 3 of the air mass types; the stronger the shear vorticity (northerly AT1 and AT3; westerly AT4) the greater the mortality.

- High wind speeds in association with low temperatures are important for increased mortality during AT1 and AT6 weather situations but these weather situations are a product of quite different synopticscale meteorological configurations.

- For AT4 and AT6, which have higher than expected mortality rates (Table 6), the weather sensitivity of mortality is different, lending credence to the notion that weather mortality relationships vary with air mass type or weather situation.

- Two of the 3 variables (ZW and S) that appear in the overall regression analysis for all days (Table 2 ) are

Table 7. Multiple stepwise linear regression results for all days by air mass type. Dependent variable: IHD mortality; independent variables: see Table 1 . $H$ - indicates sign of regression coefficient. $n$ is number of days

\begin{tabular}{|c|c|c|c|c|}
\hline AT & $\mathrm{n}$ & Variables & $r^{2}$ & $\mathrm{p}$ \\
\hline 1 & 72 & $\begin{array}{l}\text {-ZS, } \\
+ \text { +Ta15, } \\
\text { +Ws15(T-1) }\end{array}$ & 0.11 & 0.013 \\
\hline 2 & 166 & +Ta15 & 0.02 & 0.05 \\
\hline 3 & 118 & $-Z S$ & 0.02 & 0.08 \\
\hline 4 & 83 & $\begin{array}{l}+\mathrm{S} \\
+\mathrm{ZW} \\
(\mathrm{T}-1)\end{array}$ & 0.12 & 0.003 \\
\hline 5 & 71 & $\begin{array}{l}\text { No significant } \\
\text { variables }\end{array}$ & & \\
\hline 6 & 152 & $\begin{array}{l}\text { +ws15, } \\
- \text { Ta15 }_{(T-1)}\end{array}$ & 0.04 & 0.02 \\
\hline
\end{tabular}


important for explaining mortality for only 1 of the air mass types, namely AT4, while the remaining variable $\left(\mathrm{Tal5}_{(\mathrm{T}-1)}\right)$ appears as important for AT6 only (Table 7). This fact lends support to the idea that the overall regression results (Section 4.1) represent competing meteorological effects on mortality.

As the relationship between mortality and weather for the individual air mass types is generally weak and most likely a product of large intra-air mass variability in mortality, weather-mortality relationships for each air mass type were evaluated for those days falling within the upper quartile for mortality. The underlying rationale for this analysis is that the general weathermortality relationships found for all air mass days should not only be replicated in general terms for the upper quartile days but that the relationships will be stronger.

Results of the regression analyses for all days falling within the upper quartile by air mass type are shown in Table 8. Results can be summarised as follows:

- The association between weather and mortality for all upper quartile mortality days is stronger than that for all days, suggesting that elevated mortality possesses a clear meteorological signature. This is especially true for AT5 as no significant weather-mortality relationships were found in the analysis of all AT5 days.

- For all upper quartile days the variation in mortality is sensitive to rate of change variables (falling dew point temperatures, a strengthening westerly wind component and increasing wind speeds) (Table 8).

Table 8. Multiple stepwise linear regression results for upper quartile mortality days by air mass type. Dependent variable: IHD mortality; independent variables: see Table $1 . \mathrm{n}$ is number of days

\begin{tabular}{|c|c|c|c|c|}
\hline AT & $\mathrm{n}$ & Variables & $r^{2}$ & $\mathrm{p}$ \\
\hline 1 & 18 & $\begin{array}{l}- \text { Tdew9 } \\
-\mathrm{S}_{(\mathrm{T}-1)}\end{array}$ & 0.45 & 0.004 \\
\hline 2 & 41 & $\begin{array}{l}-\mathrm{dws} / \mathrm{dt} \\
-\mathrm{dT} \text { dew15/dt }\end{array}$ & 0.11 & 0.03 \\
\hline 3 & 30 & $-\mathrm{W}_{(\mathrm{T}-1)}$ & 0.08 & 0.05 \\
\hline 4 & 21 & $+Z W$ & 0.15 & 0.05 \\
\hline 5 & 18 & $\begin{array}{l}+\mathrm{du} / \mathrm{dt} \\
+\mathrm{dws} / \mathrm{dt} \\
+\mathrm{dTT} \text { a15/dt } \\
-\mathrm{SLP15}(\mathrm{T}-1)\end{array}$ & 0.64 & 0.001 \\
\hline 6 & 37 & $\begin{array}{l}\text { +ws15 } \\
-Z W \\
-T d e w 15 \\
-W\end{array}$ & 0.55 & 0.001 \\
\hline Overall: & 165 & $\begin{array}{l}-\mathrm{dT} \text { dew } 9 / \mathrm{dt} \\
+\mathrm{dW} / \mathrm{dt} \\
+\mathrm{dw} / \mathrm{dt}\end{array}$ & 0.08 & 0.001 \\
\hline
\end{tabular}

Although this contrasts with the situation for all winter days (only concurrent variables are important) (Table 2) the weather-mortality relationships are similar and relate to cool or cooling conditions and strong flows from the west. However, as for the analysis of all the winter days (Table 2) strong flows from the west are not generally associated with falling temperatures.

- The individual air mass type weather-mortality relationships for upper quartile days are stronger than for the all upper quartile days regardless of air mass type. However, there is considerable inter-air mass variation in the strength of weather-mortality relationships. This suggests that for some weather situations, the associations between high mortality and weather may be stronger than other situations, for example, AT1, AT5 and AT6 compared to AT2, AT3 and AT4.

- In most cases the variables that feature in the weather-mortality relationships for the individual air mass types (Table 7) resemble those found for all upper quartile days (Table 8). For example, the westerly wind component variable, in either its concurrent, lagged or rate of change forms, appears in the weather-mortality relationships for 4 of the 6 air mass types (Table 8).

- Clear contrasts in the relationships of weather and mortality exist between AT4/AT5 and AT6. In the case of AT4 and AT5 mortality is sensitive to increasing westerly shear vorticity (AT4) and or westerly wind component (AT5), whereas for AT6 an increasing easterly (decreasing westerly) shear vorticity in association with a strong easterly wind component are significant. In the case of AT4 and AT6 these contrasts are consistent with those found in the analysis of all days by air mass type (Table 7).

\section{AIR MASS TYPE SEQUENCES AND IHD MORTALITY}

The above analyses have revealed the importance in some cases of the role of lagged and rate of change variables in explaining IHD mortality rates. Therefore, certain air mass sequences or an evolving largescale meteorological situation, as opposed to concurrent meteorological conditions alone, may accompany high mortality rates. To test this idea all possible $3 \mathrm{~d}$ air mass type sequences were identified and the IHDINDEX on the last-day of that sequence calculated in order to identify which of the air mass sequences were associated with high last day IHDINDEX values. A limit of $3 d$ was chosen because of computational restrictions. This analysis is presented in Fig. 3, where only those sequences generating a 
last day IHDINDEX > 100 and having a frequency of greater than 10 are shown.

Immediately apparent are the high last-day IHDINDEX values for sequences 226 (124) and 444 (129). Noteworthy is the fact that AT4 and AT5 do not occur in combination with any of the other air mass types, unlike AT2 and AT6, which occur in at least 2 other sequences (Fig. 3). The occurrence of 3 sequences with only 1 air mass type indicates that persistence is a definite characteristic of the winter climatology of the study area. Climatologically, and in health terms, sequence 666 is the most important as its cumulative death toll far outweighs that of any of the other sequences; 666 occurs up to 10 times more frequently than 444, for example. Despite this, the high IHDINDEX values generated by 444 cannot be ignored. They firmly indicate that persistent AT4 conditions, characterised by blustery relatively warm moist south-southwesterly to southerly flows, a backing wind and falling pressure, as an Atlantic storm system approaches the study area, are associated with elevated IHD mortality. This corroborates the results from the overall and upper quartile AT4 regression models (Tables $7 \& 8$ ).

Sequences 226 and 622 are of interest as they represent the transition between 2 distinct anticyclonic air mass types that are distinguishable mainly on the grounds of moisture contrasts (Fig. 1b). In the former case the transition is from a situation characterised by generally cold but very humid heavily overcast weather (AT2) to below-freezing conditions occasionally associated with blustery snow showers from the east

Table 9. Air mass type sequences with a frequency of occurrence greater than 5 and a IHDINDEX $>100$

\begin{tabular}{|lrc|}
\hline Sequence & Frequency & Mean last-day IHDINDEX \\
\hline 116 & 5 & 113 \\
144 & 5 & 113 \\
166 & 8 & 108 \\
223 & 8 & 102 \\
226 & 14 & 123 \\
233 & 7 & 115 \\
323 & 5 & 119 \\
332 & 11 & 107 \\
411 & 5 & 107 \\
414 & 5 & 100 \\
444 & 12 & 129 \\
445 & 7 & 112 \\
451 & 7 & 116 \\
516 & 5 & 107 \\
555 & 13 & 113 \\
566 & 6 & 101 \\
622 & 11 & 105 \\
632 & 5 & 101 \\
645 & 6 & 117 \\
666 & 51 & 109 \\
\hline
\end{tabular}

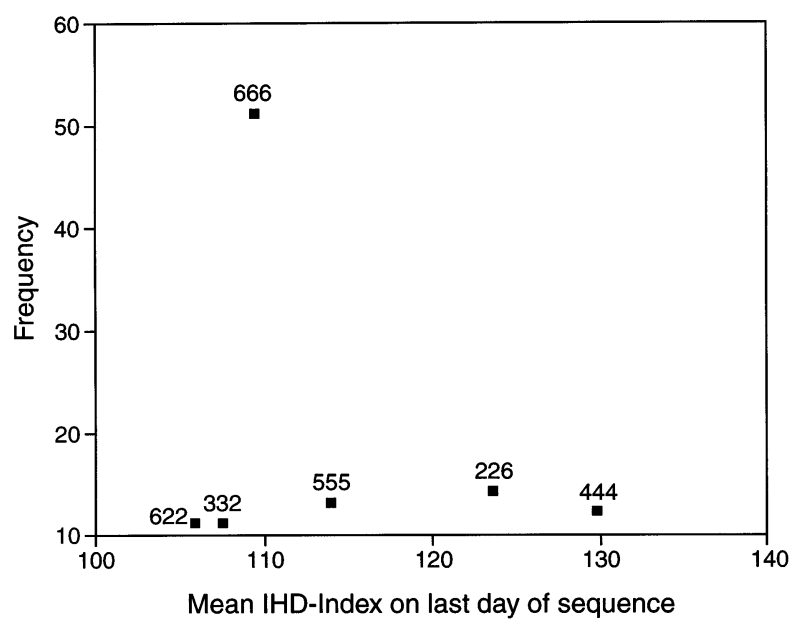

Fig. 3. Air mass type sequences and last day IHDINDEX values. All possible $3 \mathrm{~d}$ air mass type sequences were tested for high IHDINDEX values on the third day. Only INDINDEX vales $>100$ and having a frequency $>10$ are shown. Air mass type sequences are given

(AT6). In the case of 622 the opposite is true. The association of sequence 666 with high mortality confirms the regression results for the overall and upper quartile models, such that persistent cold blustery conditions from the east appear to be associated with high mortality.

Sequence 555 is the third most frequent sequence with a last-day IHDINDEX greater than 100. The AT5 upper quartile regression model indicates that weather changes associated with this sequence, especially rapidly changing wind speeds and temperatures and low atmospheric pressure as an intense sub-polar cyclonic system passes to the northeast of the UK, accompany high mortality.

The appearance of sequence 332 in Fig. 3 is also indicative of the role of weather change as, in this case, warm moderately dry southerly air with a mixed tropical maritime-continental origin (AT3) is replaced by cool moist and very stable maritime air typical of AT2 anticyclonic gloom conditions. Elevated mortality in this case may be due to falling temperatures associated with the transition from AT3 to AT2 conditions.

Although not shown in Fig. 3 a number of other sequences with frequencies equal to or greater than 5 also produced last-day IHDINDEX values $>100$ (Table 9). Notably, the majority of these are characterised by the juxtaposition of air mass type days of quite different thermodynamic attributes, highlighting the possible role of air mass change in contributing to elevated mortality levels, for example, 323, 451 and 645 , all of which produce last-day IHDINDEX values $>115$. N otably absent are persistent sequences of AT1, AT2 and AT3 as these are all associated with last-day mortality rates below the winter average. 


\section{DISCUSSION}

Based on the results from a typical linear regression based epidemiological analysis of the relationship between IHD mortality and weather, it appears that cold temperatures in conjunction with a strong southerly wind component and westerly shear vorticity are allied with mortality increases. However, for the study area, low temperatures are related to northerly or easterly flows, not southerly flows or weather systems from the west with a strong cyclonic component. Given this fact, 2 competing weather mortality effects seem to be at play, such that mortality increases are related to 2 distinct weather situations. In simple terms these can be described as cold and stormy, respectively. In order to test this supposition the relationship between mortality and weather situations was analysed. Analyses revealed contrasts amongst the air mass types in the weather sensitivity of mortality. Especially notable are the weather mortality contrasts that exist for AT4 and AT6 conditions and the sensitivity of high mortality to meteorological conditions associated with AT1 and AT5.

In the case of AT4, mortality on both all and upper quartile mortality days appears to be associated with strong southwesterly flows off the Atlantic. These conditions are related with well-developed and deepening (increasing vorticity) North Atlantic storm systems moving towards or over the UK. Imbedded in the strong moderately warm southwesterly flows are rapidly moving fronts. Over the study area falling pressures and rising temperatures are the main meteorological characteristics. Similar conditions have been found to be associated with mortality increases in Barcelona, Spain (Saez et al. 1995), and Birmingham, Alabama, USA (Kalkstein \& Davis 1989). The medical reasons for such a maritime stormy winter weathermortality relationship are not clear but may relate to the initiation of anomalous physiological and biochemical processes that occur in response to the passage of fronts and the attendant rapid meteorological changes (Curson 1996). For example, changes in blood viscosity and clotting time and the toxicity of some drugs occur with the passage of major fronts. Such biochemical and physiological responses have been linked to a higher frequency of stroke and cardiac accidents (Curson 1996). Driscoll (1971) has also noted the association of frontal passage with increased mortality.

In contrast to AT4, mortality on AT6 days is allied to strong cold winds. The strength of this relationship, as measured by the correlation coefficient, appears to be clearer for upper quartile mortality days on which strong easterly winds with low dew point temperatures explain $55 \%$ of the variation in mortality. These conditions are associated with a synoptic-scale meteorologi- cal setting quite different to that of AT4, namely a welldeveloped anticyclonic system lying to the east of the UK over Europe. This system advects cold continental polar air from the east over the UK. Such easterly flows often bring with them snow showers. In the United States similar weather situations characterised by overcast damp and snowy days and strong cold northeast flows off the Atlantic have been found to be associated with increased heart disease related mortality (Kalkstein \& Davis 1989). Certainly these conditions resemble those of AT6, especially when the trajectory of the cold polar continental air associated with AT6 is over the North Sea to the east of the study area.

The health effects of such cold weather, as found for AT6 conditions, are increases in systolic blood pressure, central blood volume and haemo-concentration (Eurowinter Group 1997) as well as a reduction in the body's thermo-regulatory efficiency (Curson 1996). These changes are of critical importance for individuals whose circulatory system is al ready under stress as the result of circulatory disease. Consequently the risk of stroke or heart attack is increased (Curson 1996) under such cold conditions. Although the importance of cold weather for determining the temporal variability of winter IHD mortality for the UK has been known for some time (Rose 1966, Bull \& Morton 1975, Keatinge et al. 1989, Langford \& Bentham 1995), the results from this analysis allow the findings from earlier UK weather-health studies to be placed in a synoptic climatological context. This is because the atmospheric setting associated with mortality-sensitive cold weather has been identified. Such information may aid in the understanding of both the inter-annual and spatial variability of cold weather related mortality. For example, it may be expected that winters with a greater occurrence of AT6 will have a higher total IHD mortality than low frequency AT6 winters. Unfortunately this hypothesis cannot be tested here because of sample size considerations. In terms of the spatial variability of weather-health relations, an air mass based analysis of other major UK and European cities may aid in the interpretation of the results from the Eurowinter Group's Pan European assessment of the relationship between cold weather and IHD mortality (Eurowinter Group 1997). In short, the Eurowinter study has shown that cold weather related IHD mortality is more acute in warmer than colder climates. This result is undoubtedly a reflection of the contrasting synoptic climatological settings of the locations considered, such that warm locations infrequently come under the influence of air masses that bring cold weather. Therefore, an understanding of the geographical distribution of the frequency of cold weather air mass types may well aid in the interpretation of the emerging pattern of contrasting weather-health rela- 
tionships found across Europe. A spatial synoptic index (Kalkstein \& Greene 1997), in contrast to the single location index used in this study, could be applied to the analysis of this climate and health issue.

As well as the direct temperature/body cooling effects on mortality associated with the occurrence of AT6, indirect effects may also be responsible for some AT6 related deaths. This is because some AT6 days are associated with snow. Deaths on such days may therefore be related to individuals over-exerting themselves while undertaking clean-up activities after snowfall. For example on the eastern seaboard of the United States mortality increases have been found following major snow blizzards (Faich \& Rose 1979, Glass \& Zack 1979).

Although AT1 and AT5 do not display markedly higher than expected daily mortality (Table 6) the associations between mortality and weather for these air mass types is of interest. This is because in the case of AT1 the basic weather-mortality relationships revealed for all days are preserved for the extreme mortality days, those with old northerly winds. In the case of AT5 days, mortality appears to be associated with rapid changes of the meteorological conditions that typify this air mass type, especially wind speed and temperature. These changes are allied to the rapid eastward movement, north of the UK, of a well-developed sub-polar low pressure system.

The analysis of air mass sequences has revealed the importance of weather situation persistence $(555,444$ and 666 ) as well as change (226 and 622) for high lastday mortality. Of interest is the fact that, although AT6 is associated with higher than expected mortality on a daily basis, it records a mean last-day-of-sequence mortality rate less than sequences 444 and 555 . This may be explained with reference to the concept of mortality displacement, such that weak individuals who may have died later are removed from the population early on in an adverse weather sequence. The persistence of severe weather therefore results in the reduction of the pool of susceptible individuals. That this is a distinct possibility is supported by evidence of below average mortality rates following a particularly severe sequence of weather associated with AT6 between February 5 and 9, 1991 (Fig. 4). During this period a $2 \mathrm{~d}$ cold wave related mortality peak was followed by $2 \mathrm{~d}$ of below average mortality. The mortality displacement or the percentage of total extra deaths associated with the cold wave (calculated as the sum of mortality after the cold wave divided by the sum of mortality during the cold wave expressed as a percentage; McMichael et al. 1996) was $51 \%(18 / 35)$. This is comparable to the scale of mortality displacement reported for a number of prolonged US heat waves (Kalkstein 1993). Inspection of the time series plot of

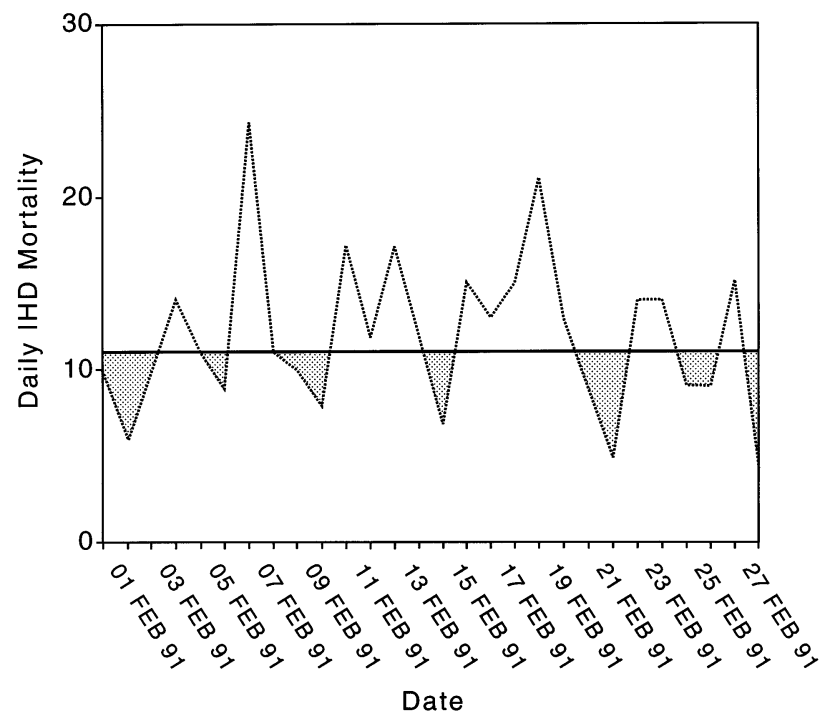

Fig. 4. Time series plot of daily IHD mortality in February 1991. Shaded areas represent days with mortality below the winter average of 10.4 deaths $\mathrm{d}^{-1}$

mortality for February 1991 also reveals a number of other short periods when mortality displacement occurred (Fig. 4).

\section{CONCLUSION}

Study results have revealed significant statistical relationships between winter air mass types or weather situations and mortality for the study area. Some air mass types favour higher than expected mortality rates. Furthermore, there is statistical evidence for weather related mortality increases in some of the air mass types. This may suggest that there may be threshold meteorological values beyond which mortality increases for certain weather situations. This requires further investigation. It also appears that increases in IHD mortality are not only associated with concurrent meteorological conditions but are related to antecedent and rapidly changing meteorological conditions at both local and large scales.

Of particular note is the fact that the 2 weather situations that are associated with a greater than expected mortality occurrence (AT4 and AT6) are starkly different in terms of their meteorological characteristics. This points to the possible existence of a degree of equifinality in weather-IHD mortality relationships, in that contrasting weather situations within a single season may produce equally high mortality rates. If so, for climatic settings characterised by changeable weather situations such as the UK, the association between weather and mortality is likely to be complex. For this 
reason a traditional epidemiological approach to the analysis of weather-mortality relationships may reveal little about the relationship between weather and mortality. This is because mortality may be sensitive to a variety of contrasting weather situations with markedly different meteorological characteristics.

An important outcome of this study relates to methodology in climate-mortality studies for middle to high latitude locations that experience a range of meteorological conditions. If all season only relationships are considered, weather-mortality relationships may be obscured. This is because high intra-seasonal mortality rates are produced by quite different weather situations. Therefore, in a conventional regression analysis, which does not partition the meteorological or health data in accordance with the major weather situations, weather-mortality signals will be masked because of competing meteorological effects. Furthermore, if the mortality data is stratified according to mortality rate level, clearer weather-mortality relationships emerge compared to an unstratified analysis.

This study has necessarily been exploratory in nature because it is based on 6 winters and 1 health outcome only. Furthermore, IHD mortality has not been stratified according to age or socio-economic class. Another limitation is that the study is limited to 1 geographical area and therefore the results may not be applicable at a larger geographical scale. These limitations form the basis for a possible future research agenda. The repetition of the study with a longer period data set would allow this study's results to be corroborated or refuted. Furthermore, the inter-annual variability of mortality rates for a range of health outcomes, among different age and socio-economic groups, could be analysed in terms of yearly air mass frequency variations. The study also needs to be extended to other geographical areas in order to establish whether the relationships found in this study also apply to the rest of the United Kingdom or indeed Europe. Finally, as IHD mortality appears to be associated with air mass characteristics and air mass sequences, then climatologists and epidemiologists should consider adopting a synoptic climatological approach to the assessment of the impact of climate change on IHD mortality and possibly other health outcomes.

\section{LITERATURE CITED}

Anto J M, Sunyer J (1986) Environmental health: a pointsource asthma outbreak. The Lancet 1:900-903

Balling RC (1984) Classification in climatology. In: Gaile GL, Wilmott CJ (eds) Spatial statistics and models. D Reidel Publishing Company, Dordrecht, p 81-108

Bucher K, Hasse C (1993) M eteorotropy and medical-meteorological forecasts. Experientia 49(9):759-768
Bull GM, Morton J (1975) Environmental temperature and death rates. Age Aging 7:210-224

Curson P (1996) Human health climate and climate change-an Australian perspective. In: Henderson-Sellers A, Giambelluca T (1996) Climate change: a southern hemisphere perspective. J Wiley and Sons, Chichester, p 319-348

Driscoll DM (1971) The relationship between weather and mortality in ten major metropolitan areas in the United States, 1962-1965. Int J Biometeorol 15:23-39

Driscoll DM (1992) Everyday weather and human response: should we be concerned? In: The Weather and Health Workshop. Environment Canada, Ottawa, p 30-39

Ebdon D (1985) Statistics in geography. Blackwell, London

Eurowinter Group (1997) Cold exposure and winter mortality from ischaemic heart disease, cerebrovascular disease, respiratory disease and all causes in warm and cold regions of Europe. The Lancet 349:1341-1346

Faich G, Rose R (1979) Blizzard morbidity and mortality: Rhode Island, 1978. Am J Pub Health 69(10):1050-1052

Glass RL, Zack M M (1979) Increases in deaths from ischemic heart disease after blizzards. The Lancet 1979:485-487

Greene J S, Kalkstein LS (1996) Quantitative analysis of summer air masses in the eastern United States and an application to human mortality. Clim Res 7:43-53

J endritzky G, Bucher K (1992) M edical-meterological fundamentals and their utilization in Germany. In: M aarouf RA (ed) Proceedings of the weather and health workshop. Environment Canada, Downsview, p 42-59

Kalkstein LS (1991) A new approach to evaluate the impact of climate upon human mortality. Environ Health Perspect 96:145-150

Kalkstein LS, Davis (1989) Weather and mortality: an evaluation of demographic and inter-regional responses in the United States. Ann Assoc Am Geogr 79:44-64

Kalkstein LS, Greene S (1997) An evaluation of climate/mortality relationships in large US cities and the possible impacts of a climate change. Environ Health Perspect 105(1):84-93

Kalkstein LS, Smoyer K (1993) The impact of climate change on human health: some international implications. Experientia 49:469-479

Keatinge WR, Coleshaw SKR, Holmes J (1989) Changes in seasonal mortalities with improvement in home heating in England and Wales from 1964 to 1984. Int J Biometeorol 33:71-76

Kilsby CS, Copertwait PSP, O'Connell PE, J ones PD (1998) Predicting rainfall statistics for England and Wales using atmospheric circulation variables. Int J Climatol 18:523-540

Langford IH, Bentham G (1995) The potential effects of climate change on winter mortality in England and Wales. Int J Biometeorol 28:141-147

Martens P (1998) Health and climate change: modelling the impacts of global warming and ozone depletion. Earthscan Publications, London

McGregor GR, Bamzelis D (1995) Synoptic typing and its application to the investigation of weather air pollution relationships Birmingham, United Kingdom. Theor Appl Climatol 51:223-236

McGregor GR, Walters S, Wordley J (1999) Daily hospital respiratory admissions and winter air mass types Birmingham. Int J Biometeorol (in press)

McMichael AJ, Haines A, Sloof R, Kovats S (1996) Climate change and human health. World Health Organisation, Geneva

Muller RA, J ackson AL (1985) Estimates of climatic air quality potential at Shreveport, Louisiana. J Clim Appl Meteorol 24:293-301 
Rose G (1966) Cold weather and ischaemic heart disease. $\mathrm{Br}$ J Prevent Soc Med 20:97-100

Saez MJ , Sunyer J , Castellsague J , M urillo C, Anto J M (1995) Relationship between weather temperature and mortality: a time series analysis approach in Barcelona. Int J Epidemiol 24:576-582

Sanchez IL (1990) Forecasting particulate matter concentrations in a city from meteorological variables and regional weather patterns. Atmos Environ 24A:1509-1519

Tout DG (1987) Biometeorology. Prog Phys Geogr 11: 476-486

Editorial responsibility: Laurence Kalkstein, Newark, Delaware, USA
Tromp SW (1980) Biometeorology: the impact of the weather and climate on humans and their environment. Heydon, London

Tselepidaki IG, Asimakopoulis DN, Katsouyanni K, Moustris C, Touloumi G, Pantazopoulou A (1995) The use of a complex thermohygrometric index in predicting adverse health effects in Athens. Int J Biometeorol 38:194-198

Tukey J W (1953) The problem of multiple comparisons. Ditto, Princeton University, Princeton, NJ

Yarnal B (1993) Synoptic climatology in environmental analysis. Belhaven Press, London

Submitted: December 8, 1997; Accepted: March 22, 1999

Proofs received from author(s): J une 11, 1999 